\title{
El enfoque praxeológico
}

Por: Carlos Germán Juliao Vargas. (2011).

Bogotá: Corporación Universitaria Minuto de Dios.

UNIMINUTO, 164pp.

Benjamín Barón Velandia

Corporación Universitaria Minuto de Dios - Bogotá, Colombia

benjaminbv@gmail.com 


\section{La praxeología: otra forma de experimentar la vida}

Carlos Germán Juliao Vargas, sacerdote Eudista, consagrado investigador en el campo del desarrollo social y sustentable, publicó en el 2011 su obra El enfoque praxeológico, obra que tiene como propósito invitar a la comunidad a dar continuidad al tema de la "praxeología" en UNIMINUTO. Ejercicio que discurre por la pedagogía de la pregunta, en donde son evidentes las interpelaciones por ¿qué es la praxeología?, ¿cuál es el concepto de acción adecuado para la investigación praxeológica?, y ¿cómo concebir el quehacer praxeológico como proceso investigativo?, hilos conductores que trascienden el entendimiento humano por los recónditos espacios del quehacer praxeológico. Desde estas cuestiones, Juliao devela la aparición de la praxeología como un esfuerzo de hermenéutica práctica, que permite la unicidad de las tres funciones sustantivas de la universidad de investigación, de compromiso social crítico y de formación profesional, todo ello inmerso en un contexto pluridisciplinario como el que vivimos en la escuela hoy día. Así parece que por fin le hemos dado fin a los determinismos, y hemos permitido la aparición en el escenario de la escuela a la apertura en las probabilidades, a la incertidumbre y a las contemplaciones más que a las afirmaciones.

La obra está matizada por el estilo característico de Juliao, sus pensamientos son plasmados en el papel con la facilidad con que discurren sus diálogos, atemporales, anacrónicos, porque no es necesario un espacio físico, ellos concurren en una dialéctica interminable, desde la facultad de educación hasta las demás facultades de UNIMINUTO. Como una diáspora que prolonga sus seudópodos y a pesar de generar siempre en los "principiantes, en quienes nos acercamos por primera vez a su obra " un hálito de incertidumbre, frente a una contemplación tan diversa sobre la realidad pedagógica e investigativa de la educación, y a una puesta en marcha de la creatividad tan Ilana como la plantea Juliao. Si es bien sabido que la obra tiene un alto componente pedagógico e investigativo, también es entendido que es posible aplicar la praxeología a todas las formas posibles del actuar humano. Ésto incluyen el desempeño profesional, porque no se limita a una autorreflexión de pedagogo o de investigador, sino que pretende hacer un auto-análisis que favorezca la construcción personal y que permita de manera permanente estar haciendo "devolución creativa o prospectiva", de manera individual, pero que a su vez redunde en beneficio de una sociedad y de un proyecto humano más sensible. El texto por donde se le mire es una fuente de luz, pero debo reconocer que las cosas que más me impactaron fueron:

Por un lado, la claridad de la escritura, con la que los conceptos navegan a través del texto, pero esto no quiere decir que sea fácil el acceso a esos nuevos mundos de conocimiento, porque Juliao lo escribe como lo dice y como lo piensa, 
pero al interior, exige en comprensión. Esto se debe a que mantiene la dinámica continua planteada en los cuatro momentos de la praxeología: ver, juzgar, actuar, y la devolución creativa o prospectiva. Por consiguiente, se realiza un tejido, que genera nuevas conexiones y que trasciende las fronteras del espíritu mecanicista, representacionista y verificacionista de resultados. Nosotros como hijos propios de la sociedad moderna, que en procura de una idea de objetividad científica, desvincula al sujeto y lo sustrae de su relación, es decir, donde el sujeto es ajeno al acontecimiento vital, donde se genera una dualidad irreconciliable de su complexión, al respecto Juliao señala:

La búsqueda de un fundamento universal asume formas diversas, que privilegian al mundo externo (objetivismo) o las representaciones como medida de todas las cosas (idealismo). Así, al tomar la mente y el mundo como polos opuestos, la ansiedad cartesiana se mueve, permanentemente, entre el objetivismo y el subjetivismo (Juliao, 2011, p. 53).

Esos esfuerzos representados en una dinámica que privilegia el pensamiento como custodio del conocimiento, ante las amenazas latentes a las que perennemente esta expuesto: doxa, prejuicios y tradiciones que no tengan a la razón como el cedazo a través del cual se filtran las realidades. Ese dato primario que da la razón, se ha endiosado, durante largo tiempo, bajo el concepto de representación objetiva de la realidad. Como en la teoría del espejo o isomorfismo, entendida desde Wittgenstein en el Tractatus, quien la plantea como una de sus aserciones principales, "De lo que no se puede hablar, es mejor callar". Como si se tratara de lo inhóspito del conocimiento, o como si aún existieran dogmas que son permitidos para unos y para otros no.

Por otro lado, Juliao, en su enfoque praxeológico, hace un gran aporte en relación con los límites del conocimiento y de las maneras como el sujeto se construye en la interacción con los otros. Apoyándose en Freire, señala que nadie enseña a nadie porque nadie aprende de nadie, ya que el conocimiento es un proceso de construcción colectiva, donde los sujetos hacen de la acción no un nuevo concepto o una nueva palabra, sino como lo plantea Maturana (1992) un lenguaje. Es allí, donde esa comprensión tiene un lugar fundamental en las relaciones y se ubica en el ámbito de las coordinaciones de acción como una forma de fluir en ellas, no como algo que está en ellas. Ese vibrar existente en las relaciones, se da en la diferencia, ya que esto es lo que nos permite contemplar al otro y su mismidad, sin homogeneizarlo.

Para Juliao, ese sentido de entender la acción es abordado desde otras miradas, desde otras culturas, desligándose de la tradición occidental, que limita y coarta la aparición del sujeto implicado en términos de Bohm (1992), en este caso, se asume el tema de la meditación de la consciencia intuitiva, emanada del budismo. Desde allí, se movilizan los cimientos de la tradición, que durante muchos siglos nos enseñaron a hablar de los fenómenos como hechos estáticos y poseedores de certidumbres. 
De esta manera, nos centramoss en un nuevo paradigma, que lee ese horizonte en términos Freirerianos: "de la infertilidad de la certidumbres a la fertilidad de las incertidumbres". Un nuevo horizonte, desde donde las incertidumbres generan escenarios de fertilidad y y llenos de vacuidad.

Cuando nos referimos al conocimiento que emana en la acción, recurrimos a Schön (1987) quien hace una distinción básica de dos componentes: el primero, relacionado con el saber proposicional, que es un aspecto teórico que corresponde a lo adquirido a través de la universidad, lo que conocemos como enciclopedismo. El, segundo es el saber-en-la-acción, el cual emana de la práctica profesional, comprendido como lo tácito, espontáneo y dinámico, que por naturaleza se hace devolución creativa porque busca la generación de una acción más transformadora. que revierta en la sociedad, en un nuevo sujeto capaz de generar un conocimiento útil. En otras palabras, no se trata de pensar o de racionalizar, es más de vivir, es una nueva experiencia vital que propenda por la dinámica de procesos, más que por el interés de los resultados.

Para los maestros, investigadores y para todo aquel interesado en el tema de la construcción de subjetividades reflexivas, este texto es un referente importante, porque más allá de convertirse en un manual o un dossier que nos brinde pautas para hacer "prácticas praxeológicas", invita al desarrollo de la creatividad, que con el tiempo se ausenta de los escenarios de vida del desempeño y en especial de la escuela. Es imprescindible que esta obra pueda encontrar una morada, no en los anaqueles de las bibliotecas de universidades, instituciones educativas o personales, sino que a través de los diversos medios de socialización, como las tecnologías de la información y la comunicación, se pueda propagar y encontrar como libro de trabajo. 


\section{Referencias}

Bohm, D. (1992). La Totalidad y el Orden Implicado. Barcelona: Kairós.

Humberto, M. (1992) Emociones y lenguaje en Educación y Política (6 $6^{a}$ Ed.). Santiago: Ediciones Pedagógicas Chilenas.

Schön, D. A. (1987). La formación de profesionales reflexivos. Hacia un nuevo diseño de la enseñanza y el aprendizaje de las profesiones. Barcelona: Paidós.

Wittgenstein, L. (2009). Tractatus logico-philosophicus. Madrid: Alianza Editorial, 